\title{
The polypharmacy reduction potential of cinnamic acids and some related compounds in pre- and post-onset management of type 2 diabetes mellitus
}

\author{
Douglas Edward Barre, Kazimiera Amelia Mizier-Barre \\ Department of Health Sciences, Cape Breton University, Sydney, Nova Scotia, Canada \\ E-mail:ed_barre@cbu.ca
}

Objectives. This review assesses the polypharmacy reduction potential of cinnamic acids (CAs) and some related compounds in managing three or more of the cluster of seven, pre- and post-type 2 diabetes mellitus (T2DM)-related features (central obesity, hyperglycemia, hypertension, dyslipidemia, pro-thrombosis, oxidation, and inflammation).

Methods. Google scholar and Pubmed were searched for cinnam*, chlorogenic acid, ferulic acid, and caffeic acid in conjunction with each of pre- and post-onset T2DM, central obesity, hyperglycemia, hypertension, dyslipidemia, pro-thrombosis, oxidation, and inflammation. The study was divided into an introduction followed by findings on the impacts of each of the CAs including trans-CA acid, the E isomer of a CA-based thiazolidinedione and a metabolite of that isomer, as well as p-methoxy CA, various cinnamic amides and some other CA-related compounds (chlorogenic acid, cinnamaldehyde, ferulic and caffeic acid).

Results. Trans-CA has a potential to manage three, while each of chlorogenic acid, cinnamaldehyde, caffeic acid and ferulic acid has a potential to manage all seven members of the cluster. Other CA-related compounds identified may manage only one or two of the cluster of seven.

Conclusions. Much of the work has been done in animal models of pre- and post-onset T2DM and non-pre- or post-onset T2DM humans and animals, along with some cell culture and in vitro work. Very little work has been done with human pre- and post-onset T2DM. While there is potential for managing 3 or more members of the cluster with many of these compounds, a definitive answer awaits large pre- and post-T2DM onset clinical trials with humans.

Key words: cinnamic acids and related compounds, type 2 diabetes mellitus, central obesity, hyperglycemia, hypertension, dyslipidemia, pro-thrombosis, oxidation and inflammation

Central obesity is frequently a start of the cascade of events leading to a cluster of hyperglycemia, hypertension, dyslipidemia (most often decreased plasma/ serum high density lipoprotein cholesterol (HDLc) and increased triglycerides, but also sometimes increased cholesterol and low density lipoprotein cholesterol (LDLc)), pro-thrombosis, increased oxidation including that of LDL and subsequent inflammation, all of which frequently lead to or are the part of type 2 diabetes mellitus (T2DM) (Steinberg 1992;
Erkelens 2001; Beckman et al. 2002; Gresele et al. 2003; Carr and Brunzell 2004; Krauss 2004; Dandona et al. 2005; Avogaro et al. 2006; Boudjeltia et al. 2006; Grundy 2006a,b; Wright et al. 2006; Azuma et al. 2007; Devaraj et al. 2007). In addition, the sequential pathway, if unchecked, leads to a progressive spiraling of loss of glycemic control (Dandona et al. 2005). The search for new agents to combat three or more of the seven features contributing to and/or being part of $\mathrm{T} 2 \mathrm{DM}$ post-onset continues as numerous problems 
with polypharmacy have been reported (Austin 2006; van Bruggen et al. 2009; Dunn 2010; Huang et al. 2010). Grundy (2006a,b) has suggested a single drug or single combination of drugs would be helpful in pre- and post-onset T2DM managed by polypharmacy reduction.

The $\mathrm{E}$ isomer of a CA-based thiazolidinedione and a metabolite of that isomer as well as p-methoxy CA, various cinnamic amides, chlorogenic acid, cinnamaldehyde, ferulic and caffeic acids are compounds in this family that have received the most attention. However, a review of the literature in terms of the potential of CAs and some of their related compounds to combat the cluster of seven has not been done and so it is important to assess whether such potential exists.

The purpose of this review is to discuss evidence or note lack thereof for the use of CAs and some of their related compounds in polypharmacy reduction in terms of safely and efficaciously combatting three or more members of the aforementioned seven features in both pre- and post-T2DM onset in the short and long term.

\section{Impact of CAs and some of their related com- pounds on the cluster of seven and T2DM}

It appears that there are not available any reports on the impact of CAs on central obesity in terms of prevention or post-onset management in humans, but in high fat diet fed rats an unspecified CA reduced the extent of weight gain (Mnafgui et al. 2015). Barre et al. (2012) have found that consumption of flaxseed lignan complex (FLC) containing unspecified CAs also diminished waist circumference gain though such results cannot be unquestionably assigned to the CAs as other compounds were in the FLC. Cinnamaldehyde lowered body weight in $\mathrm{db} / \mathrm{db}$ mice (a T2DM model) (Li et al. 2012), but it is not clear if that is represented by a fat mass reduction. Similarly, Huang et al. (2011) have found that cinnamaldehyde administration to high fat diet fed Institute of Cancer Research (ICR) mice resulted in slower weight gains but again, there was no specific indication of fat mass gain reduction though they were able to show cinnamaldehyde-induced lipid accumulation reduction in 3T3 L1 differentiated adipocytes. Along those lines, Khare et al. (2016) have observed reduced lipid accumulation in mature adipocytes after cinnamaldehyde was incubated with 3T3 L1 pre-adipocytes. The reduced lipid accumulation was due, at least in part, to a shift toward lipolysis. Khare et al. (2016) have also noted a cinnamaldehyde decrease in weight in high fat fed Swiss male albino mice due at least in part to a decreased serum leptin:ghrelin ratio. Such a combination of these hormones reduced weight regain in a group of overweight and obese humans (Crujeiras et al. 2014). Thus, cinnamaldehyde may be important in weight management and reducing adipose tissue lipid accumulation hence reducing the risk of T2DM. Ferulic acid suppressed obesity and visceral fat accumulation (de Melo et al 2017) and hepatic fat (Wang et al. 2018) in high fat diet-induced obese mice.

Chlorogenic acid is poorly absorbed ( $1 / 3$ across the small intestinal wall in humans (Olthof et al. 2001; Gonthier et al. 2006) due to its quinic acid group (chlorogenic acid is derived from the esterification of quinic acid to caffeic acid). However, chlorogenic acid can be metabolized by the human microbiome to caffeic acid among other metabolites (Gonthier et al. 2006; Bel-Rhlid et al. 2013; Tomas-Barberan et al. 2014). Yet, Del Rio et al. (2010) have indicated that most of the catabolism of chlorogenic acid to caffeic acid occurs at the small intestine. Indeed, Del Rio et al. (2010) have pointed out that most of the absorption of caffeic and ferulic acid also occurs at the small intestine with some absorption also occurring at the colon. The findings of Del Rio et al. (2010) have stood in sharp contrast to Plumb et al. (1999) who have posited that all of the chlorogenic acid esterase activity was in the microbiome of the large intestine. However, Plumb et al. (1999) did tissue extract work rather than the more reliable in vivo work of Del Rio et al. (2010) who have compared humans with ileostomies to those with intact colons. Regardless, the important outcome is the chlorogenic acid esterase activity and not its location as chlorogenic acid metabolites contribute to management of the cluster of seven along with chlorogenic acid. Chlorogenic acid administered in a double-blind randomized placebo-controlled study to impaired glucose tolerance patients for 12 weeks resulted in mild waist circumference reduction (Zuniga et al. 2018). Meng et al. (2013) in a review paper indicated that chlorogenic acid could suppress weight gain in mice, while Bhandarkar et al. (2019) have found that chlorogenic acid consumption reduced energy intake, waist circumference, and visceral adiposity in rats fed a high carbohydrate, high fat diet. Cho et al. (2010) have found reduced body weight, visceral fat mass, and plasma leptin due to each of chlorogenic acid and caffeic acid intake in high fat diet-induced obesity in mice. Park et al. (2017) have noted in humans that chlorogenic acid increased fat oxidation during sleep and thus could control obesity. Whether it is chlorogenic acid and/or caffeic acid that contributes to these outcomes is not clear. 
Adisakwattana (2017) has noted that CA and their derivatives have glucose management potential in humans via different mechanisms that include increased insulin secretion, better pancreatic $\beta$-cell function, hepatic gluconeogenesis inhibition, better glucose uptake, strengthened post-insulin binding intracellular signaling mechanisms, delayed carbohydrate digestion and absorption, and decreased protein glycation and insulin fibrillation. Various CAs have been identified as alpha-glucosidase inhibitors (Adisakwattana et al. 2004, 2009), which have the potential to lower blood plasma glucose levels via delayed small intestinal carbohydrate digestion (Caspary 1978; Caspary and Graf 1979). Hafizur et al. (2015) have found that trans-CA improved glucose tolerance in vivo in streptozotocin-induced T2DM rats and increased insulin secretion in isolated mice islets. Interestingly, a CA-based thiazolidinedione decreased serum glucose in $\mathrm{db} / \mathrm{db}$ mice (Arlt et al. 2004). Along those lines of thought, Neogi et al. (2003) have found that the E-isomer of a CA-based thiazolidinedione, and a metabolite of that compound, lowered blood glucose in ob/ob mice (a cell culture study using HEK293 cells done by these authors as part of the same study suggested PPAR $\gamma$ activation as a mode of action for these two agents). Furthermore, Yoo et al. (2012) have found that an intraperitoneal dose of $150 \mathrm{mg} / \mathrm{kg}$ body weight/day of an unspecified CA decreased fasting blood glucose levels in db/db T2DM model mice. Lowering of fasting blood glucose in nonobese T2DM rats consuming CA occurs in a manner comparable to the sulphonylurea, glibenclamide; as well CA increased glucose-stimulated insulin secretion from isolated pancreatic islets as noted in a review paper (Cicero and Colletti 2016). Wang et al. (2015) have observed that trans-CA lowered serum glucose in alloxan-induced T2DM in rats and indicated that increased insulin secretion and activation of Glut- 4 may be the explanation for such. As well Kopp et al. (2014) have noted trans-CA increased adiponectin secretion by 3T3-L1 adipocytes, and in these cells, phosphorylation of adenosine monophosphate activated protein kinase (AMPK)-activated protein kinase via G-protein-coupled receptor signaling; adiponectin and phosphorylation of AMPK-activated via G-protein-coupled receptor increases glucose uptake (Kadowaki and Yamauchi 2005). Lakshmi et al. (2009) have found that GLUT-4 mRNA expression was increased in L6 myotubes exposed to an unspecified CA [GLUT-4 is essential to the uptake of glucose by skeletal muscle cells (L6 myotubes are derived from rat skeletal muscle)]. The above-mentioned observations may be consistent with the findings of Barre et al. (2012) who have found that with FLC (containing unspecified CAs) administration to T2DM patients, there was lower fasting plasma glucose; however, such results may have been due to other FLC components. In addition, chlorogenic acid inhibits pancreatic $\alpha$-amylase in vitro, a contributor to small intestinal carbohydrate digestion and hence blood glucose levels (Funke and Melzig 2006). Huang et al. (2009), using a non-specified CA and one of its related compounds, caffeic acid, have found that they improved glucose uptake in TNF- $\alpha$ induced insulin-resistant mouse hepatocytes while Adisakwattana et al. $(2005,2008)$ have found that p-methoxyCA and other CA related compounds increased plasma insulin and decreased plasma glucose in normal and streptozotocin-induced T2DM rats. Adisakwattana et al. (2005) have suggested that p-methoxyCA administered to streptozotocin-induced T2DM rats increased insulin secretion and glycolysis and decreased gluconeogenesis, all of which are important in lowering plasma glucose concentrations.

Madsen and Westergaard (2001), in a review, have found potential for hyperglycemia reduction in that chlorogenic acid is an in vitro inhibitor of glucose-6-phosphatase; such inhibition contributes to reduced glycogen breakdown and hence ultimately decreased hepatic glucose release into plasma. In a review paper, Meng et al. (2013) have indicated that chlorogenic acid could be used for improved glucose control; suggested mechanisms included a-glucosidase inhibition, elevated AMPK (an energy level sensor gauge and energy balance regulator) (Kahn et al. 2005), which increases GLUT-4 glucose capture in certain cells (supported in rat skeletal muscle (Kurth-Kraczek et al. 1999), isolated soleus muscle from diabetic mice (increased glucose uptake) and in cultured L6 myotubes (AMPK mediated GLUT-4 glucose capture) (Ong et al. 2012). Inhibition of hepatic glucose-6-phosphatase in $\mathrm{db} / \mathrm{db}$ mice fed chlorogenic acid was also noted by Meng et al. (2013). Such inhibition decreases gluconeogenesis and hence glucose release into the blood (Ong et al. 2013). Van Dijk et al. (2009) have found that consumption of 1 $\mathrm{g}$ of chlorogenic acid $30 \mathrm{~min}$ before an oral glucose tolerance test in 15 overweight men resulted in lower glucose and insulin concentrations at $15 \mathrm{~min}$ after the consumption of glucose. Consistent with this is that chlorogenic acid administered to impaired glucose tolerance patients for 12 weeks resulted in better fasting plasma glucose concentration and an insulinogenic index reduction compared to baseline in the chlorogenic acid group (no changes in these parameters occurred in the placebo group) (Zuniga et al. 2018). Cho et al. (2010) have observed decreased 
plasma insulin concentrations due to each of chlorogenic acid and caffeic acid intake in high fat dietinduced obesity in mice suggesting their potential for hyperglycemia management. However, NyambeSilavwe and Williamson (2018) have found chlorogenic acid to be a weak in vitro inhibitor of human salivary a-amylase, relative to Acarbose; human salivary $a$-amylase is a contributor to the availability of glucose for intestinal absorption and hence blood glucose control. Caffeic acid and chlorogenic acid inhibit $\alpha$-amylase and $\alpha$-glucosidase in vitro, each of which contribute to the rise of free glucose available of intestinal absorption thus helping to manage plasma glucose concentrations (Oboh et al. 2015). Of these caffeic acid was better at inhibiting $\alpha$-amylase (consistent with Nyambe-Silavwe and Williamson 2018) and a-glucosidase (Oboh et al. 2015). Regrettably, neither caffeic nor chlorogenic acids have be tested in vivo in humans regarding a-amylase and a-glucosidase activity modulation so their effectiveness in managing human blood glucose levels via inhibition of these two enzymes remains unknown. Jung et al. (2006) have noted a decrease in fasting blood glucose in $\mathrm{db} / \mathrm{db}$ mice receiving caffeic acid in part due to increased adipose Glut- 4 expression and decreased hepatic glucose-6-phosphatase and phosphoenolpyruvate carboxykinase activities.

Ferulic acid decreased blood glucose in $\mathrm{db} / \mathrm{db}$ mice (Jung et al. 2007) associated with increased plasma insulin and increased hepatic glycogen synthesis. Jung et al. (2007) have also noted that ferulic acid inhibited baker's yeast $\alpha$-glucosidase in vitro (unfortunately the potential of ferulic acid's inhibition of human a-glucosidase by humans has apparently not been assessed). Devi et al. (2018) have proposed, via molecular docking studies, that ferulic acid can inhibit glycogen synthase kinase-3 (GSK-3). GSK-3 is an inhibitor of glycogen synthase (GS) and a negative regulator of the insulin signaling pathway. Thus GSK-3 inhibition increases the activity of GS and increases the activity of the insulin signaling pathway thus reducing blood glucose levels. Decreased blood glucose and increased serum insulin occurred in streptozotocin-induced T2DM male rats given ferulic acid (Roy et al. 2013). However, ferulic acid has yet to be tested in T2DM patients or in those at risk of T2DM.

Cinnamaldehyde is a derivative of CA and in streptozotocin-induced T2DM male Wistar rats was found to lower fasting plasma glucose levels and HbAlc (Babu et al. 2007). A decreased blood glucose observation has been made by $\mathrm{Li}$ et al. (2012) using cinnamaldehyde in $\mathrm{db} / \mathrm{db}$ mice which may in part been due to the increased GLUT-4
mRNA expression observed by them in skeletal muscle of these animals. Furthermore, cinnamaldehyde administration to high fat diet-induced obese ICR mice resulted in lower plasma glucose levels (Huang et al. 2011). Abdelmageed et al. (2019) have found in a streptozotocin-induced T2DM rat model that cinnamaldehyde administration resulted in improved oral glucose and insulin tolerance as well as decreased fasting blood glucose, fasting blood insulin, HOMA-IR and increased HOMA- $\beta$ index. The results were deemed attributable to increased activity of the insulin receptor substrate 1 (IRS) 1/ phosphatidylinositol 3-kinase (PI3K) regulatory subunit 1/AKT serine/threonine kinase (AKT 2) pathway arising from increased expression of these proteins in the hepatic tissue of these animals. Kostrzewa et al. (2019) have indicated in an in vitro study that cinnamaldehyde had the potential to increase insulin sensitivity by inhibiting protein tyrosine phosphatase $1 \mathrm{~B}$ thus potentially preventing T2DM or managing post-onset T2DM.

Cinnamaldehyde lowers diastolic blood pressure in insulin-resistant and insulin deficient male Wistar albino rats and systolic pressure in these insulin-deficient rats (El-Bassossy et al. 2011). Zhao et al. (2012), in a review paper, have indicated that ferulic acid-stimulated nitric oxide synthesis and angiotensin converting enzyme (ACE) inhibition that could lower systolic blood pressure in spontaneously hypertensive rats (SHR). Nitric oxide and inhibition of ACE act as vasodilators (Brown and Vaughan 1998; Chen et al. 2008), which allow blood pressure reduction. Ferulic appears better at lowering blood pressure than caffeic acid (Zhao et al. 2012). Interestingly, caffeic acid is a metabolite of chlorogenic acid (Zhao et al. 2012) suggesting the potential for chlorogenic acid administration in hypertension management. Agunloye and Oboh (2018) have indicated that chlorogenic acid and caffeic acid can inhibit plasma ACE in hypercholesterolemic rats. Unfortunately, Agunloye and Oboh (2018) did not measure blood pressure in these hypercholesterolemic rats. However, Bhandarkar et al. (2019) found that chlorogenic acid consumption decreased systolic pressure in male Wistar rats fed a high carbohydrate, high fat diet. Unfortunately, there appear to be no reports on the pre- or post-T2DM onset hypertension management by any of the CAs or their related compounds in humans.

Yoo et al. (2012) have found that an unspecified intraperitoneal dose of an unspecified CA $(150 \mathrm{mg} / \mathrm{kg}$ body weight) in $\mathrm{db} / \mathrm{db}$ T2DM mice decreased plasma cholesterol, LDL-c and triglycerides, and increased HDL-c. Wang et al. (2015) have found decreased 
serum total cholesterol and triglycerides as the result of oral consumption of trans-CA in rats with alloxaninduced T2DM. These lipid levels were not changed in the human T2DM studies by Barre et al. (2012) and Pan et al. (2007) suggesting that the presence of CAs in the Barre et al. (2012) and Pan et al. (2007) studies was not sufficient to effect such changes. Cinnamate increases plasma HDLc, the HDLc:total cholesterol, and decreases total cholesterol and hepatic cholesterol (the lattermost via 3-hydroxyl-3-methyl-glutaryl CoA reductase inhibition) in high cholesterol-fed rats (Lee et al. 2003). Ferulic acid decreased plasma cholesterol and LDL cholesterol in db/db mice (Jung et al. 2007) and decreased serum cholesterol and triglycerides in streptozotocin-induced T2DM rats (Roy et al. 2013). Cinnamaldehyde increased serum HDLc in $\mathrm{db} / \mathrm{db}$ mice (Li et al. 2012). Cinnamaldehyde when administered to streptozotocin-induced type 2 diabetic male Wistar rats was found to lower serum cholesterol and triglyceride levels and elevate plasma HDL-c concentrations (Babu et al. 2007). Similarly, cinnamaldehyde administration to high fat diet-induced obese ICR mice resulted in lower plasma fasting cholesterol and triglyceride levels (Huang et al. 2011). In a review paper that discussed the impacts of chlorogenic acid on lipid management, Meng et al. (2013) have noted that chlorogenic acid inhibits hepatic $\beta$-hydroxy- $\beta$ methylglutaryl-coenzyme A reductase in the livers of high fat diet-fed mice and in primary cultured rat hepatocytes thus helping to control plasma cholesterol levels. Agunloye and Oboh (2018) have indicated that chlorogenic acid decreased plasma cholesterol, LDL-c, and triglycerides while elevating HDLc in the hypercholesterolemic rats used in their study. Cho et al. (2010) have found reduced plasma cholesterol and triglyceride concentrations but no change in HDL-c concentrations due to each of chlorogenic acid and caffeic acid intake in high fat diet-induced obesity in mice. Chlorogenic acid administered to impaired glucose tolerance patients for 12 weeks resulted in lower plasma total cholesterol, LDL-c and triglycerides compared to baseline in the chlorogenic acid group (the placebo group showed no changes in any of these parameters) (Zuniga et al. 2018). Lee et al. (2004) have found that certain cinnamic amides could inhibit, in vitro, human acyl CoA:cholesterol acyl transferase 1- and 2- thus giving the potential for plasma cholesterol lowering.

Trans-CA, caffeic acid and ferulic acid lowered human platelet aggregation in vitro (Hubbard et al. 2003) as did chlorogenic acid (Amin et al. 2013). Lu et al. (2015) have noted that caffeic acid lowered mouse thrombus formation in vivo. Whether the significantly increased bleeding time, representative of lowered platelet reactivity, in the study by Barre et al. (2012) was due, in whole or in part, to any of the CAs present in the FLC is not clear. Pre-onset T2DM management of platelet hyperreactivity and hence shorter bleeding times has apparently not been studied in terms of CAs or their related compounds. Huang et al. (2007) have observed that cinnamaldehyde lowered platelet aggregation and thrombus formation in rats and mice.

Lee et al. (2004) have demonstrated antioxidant potential by three CA-related compounds (4-hydroxyCA (L-phenylalanine methyl ester) amide, 3, 4-dihydroxyhydroxyCA (L-aspartic acid dibenzyl ester) amide and 3, 4-dihydroxyhydroxy CA (L-alanine methyl ester) amide) against LDL oxidized with copper sulphate. However, Barre et al. (2012) did not find a decrease in LDL apoprotein B oxidation suggesting that any antioxidant effect would be CA or CA related compounds- or dose of each-specific i.e. not necessarily the CAs found in FLC. Various CAs have been reported to have a weak antioxidant impact relative to vitamin $\mathrm{E}$ using a linoleic acid model (Foti et al. 1996). Oxidized fatty acids are proposed to contribute to LDL's atherogenicity (Witztum and Steinberg 1991) and are thus worthy of in vivo assessment. Cinnamate decreased lipid peroxidation in high cholesterol diet- fed rats (Lee et al. 2003). However, no one appears to have published on the impact of CAs or their related compounds on lipid peroxidation pre- or post-T2DM onset in humans. Caffeic acid-induced oxidation reduction in the liver and erythrocytes of $\mathrm{db} / \mathrm{db}$ mice (Jung et al. 2006) may have contributed to the finding of improved glucose management in $\mathrm{db} / \mathrm{db}$ mice. In a review paper, Meng et al. (2013) have noted the serum antioxidant impact of chlorogenic acid in hyperlipidemic mice. Agunloye and Oboh (2018) indicated that chlorogenic acid had antioxidant properties in the hypercholesterolemic non-diabetic rats used in their study. Pari et al (2010) noted that chlorogenic acid decreased oxidation and inflammation in streptozotocin-induced T2DM male Wistar rats.

There appear to be no reports of CAs or their related compounds preventing or managing inflammation in pre- or post-onset human T2DM. Li et al. (2012) have observed a decrease in the pro-inflammatory cytokine TNF- $\alpha$ mRNA expression in adipose tissue of $\mathrm{db} / \mathrm{db}$ mice fed cinnamaldehyde. Abdelmageed et al. (2019) have found, in a streptozotocin-induced T2DM rat model, that cinnamaldehyde administration resulted in reduced oxidation arising from increased hepatic and aortic superoxide dismutase 
activity and increased glutathione. As well, decreased advanced glycation end products and expression of the receptor for these end-products was observed (Abdelmageed et al. 2019). The interaction of advanced glycation end products with their receptor has been linked to increased oxidation and inflammation (Schmidt et al. 2000). In that regard, Toma et al. (2017) have noted that caffeic acid reduced inflammation caused by glycated LDL in human endothelial cells (the advanced glycation end products receptor expression was also reduced by caffeic acid). Ferulic acid decreased lipid oxidation in pancreatic tissue and pro-inflammatory cytokines interleukin-1 $\beta$ (IL-1 $\beta$ and tissue growth factor- $\beta 1$ (TGF- $\beta 1$ ) expression in pancreatic beta cells in streptozotocin-induced T2DM rats (Roy et al. 2013). Furthermore, Khare et al. (2016) have observed, in male Swiss albino mice, a cinnamaldehyde-induced decrease in serum IL-1 $\beta$, a pro-inflammatory cytokine that has been linked to poor glucose management. It has been suggested that IL-1 $\beta$ may have a role in T2DM onset (Zhao et al. 2014) and in glucose management post-T2DM onset (Cavelti-Weder et al. 2016). As such cinnamaldehyde may have a role to play in pre- and post-onset T2DM management.

A summary of the potential impacts of CAs and some of their associated compounds is found in Tables 1-7.

\section{Conclusions}

CAs (trans- and unidentified), an $\mathrm{E}$ isomer of CA-based thiazolidinedione and a metabolite of that isomer and a metabolite of that isomer, as well as p-methoxy CA, various cinnamic amides, chlorogenic acid, cinnamaldehyde, ferulic and caffeic acid are the compounds in this group of CAs and related compounds that have received the most attention. Unfortunately, relatively little work has been done with human pre- and post-onset T2DM with these compounds. Success in improving managing obesity, hyperglycemia, pro-thrombosis, and inflammation has been realized in one human post-onset T2DM trial and hyperglycemia in a second trial human post-onset T2DM trial both with FLC containing CAs, but those trials did not give pure CAs thus rendering impossible any conclusion about their impact. Trans-CA inhibits healthy human platelet aggregation in vitro and improves hyperglycemia and dyslipidemia in T2DM model rats. Chlorogenic acid has shown some promise in obesity, hyperglycemia and dyslipidemia in pre-T2DM onset humans with some suggestion of hyperglycemia manage- ment in post-T2DM onset. Much of the chlorogenic acid work in mammals has been done in non-preor post-T2DM model onset mice and rat models. In that regard, all but pro-thrombosis and inflammation can be managed by chlorogenic acid. Chlorogenic acid decreased inflammation in T2DM model rats and decreased in vitro platelet aggregation in healthy humans. Cinnamaldehyde, has not been investigated in humans but has been largely investigated in T2DM model rats and mice where all but pro-thrombosis management have shown success. Cinnamaldehyde decreased thrombus formation in non- pre- or post-T2DM rats and mice. Ferulic acid has not been investigated in humans except for success with in vitro platelet inhibition in healthy humans but has shown promise in all, but obesity, hypertension and pro-thrombosis in post-onset T2DM model rats and mice. Spontaneously hypertensive (non-pre- or post-onset T2DM) rats have angiotensin converting enzyme inhibition and thus potential to lower blood pressure in response to ferulic acid. Ferulic acid improves hyperglycemia, dyslipidemia, oxidation and inflammation in nonpre-or post-onset T2DM animals and decreases in vitro platelet aggregation in healthy humans. Caffeic acid improved all but oxidation and inflammation in non-pre- or post-onset T2DM rats or mice and only promise in post-T2DM onset mice model in terms of hyperglycemia and oxidation, but again there have been no human trials. With regard to all CAs and their associated compounds discussed herein, relatively little has been done with cell culture and in vitro work, but such studies are supportive of animal and/or human studies. Trans-CA has the potential to manage three, while each of chlorogenic acid, cinnamaldehyde, caffeic acid and ferulic acid have the potential to manage seven of the cluster of seven. Other compounds identified at best have potential to manage only one or two of the cluster of seven. There appear to be no reports on cis-CA. However, until many large pre- and post-T2DM onset human trials are undertaken, it is clear that there is insufficient information for the use of CAs and some of their related compounds in polypharmacy reduction in terms of safely and efficaciously combatting three or more members of the aforementioned seven features in both pre- and post-T2DM onset in the short and long term.

\section{Acknowledgments}

For this literature review no funding support was received from any source. 


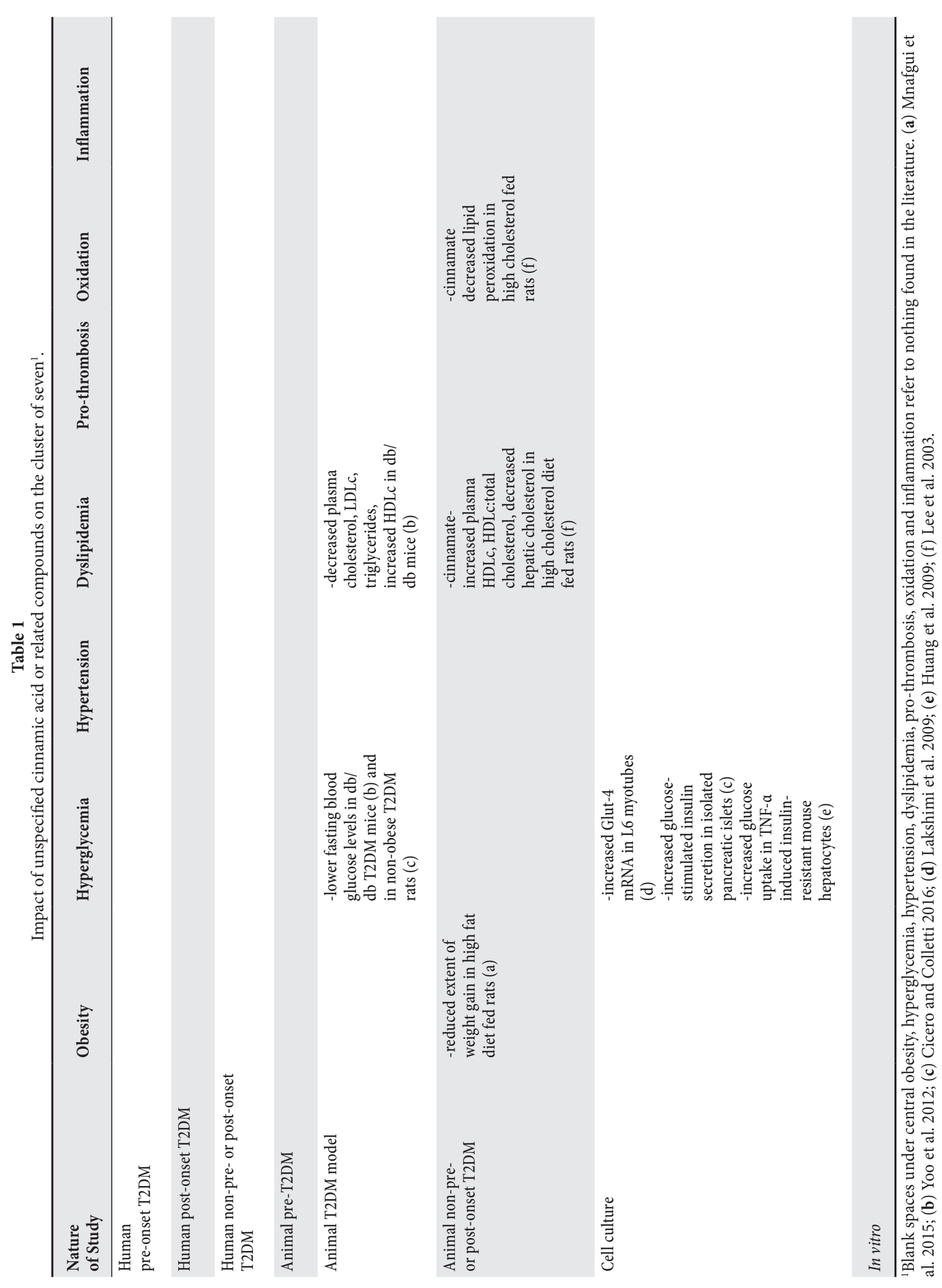




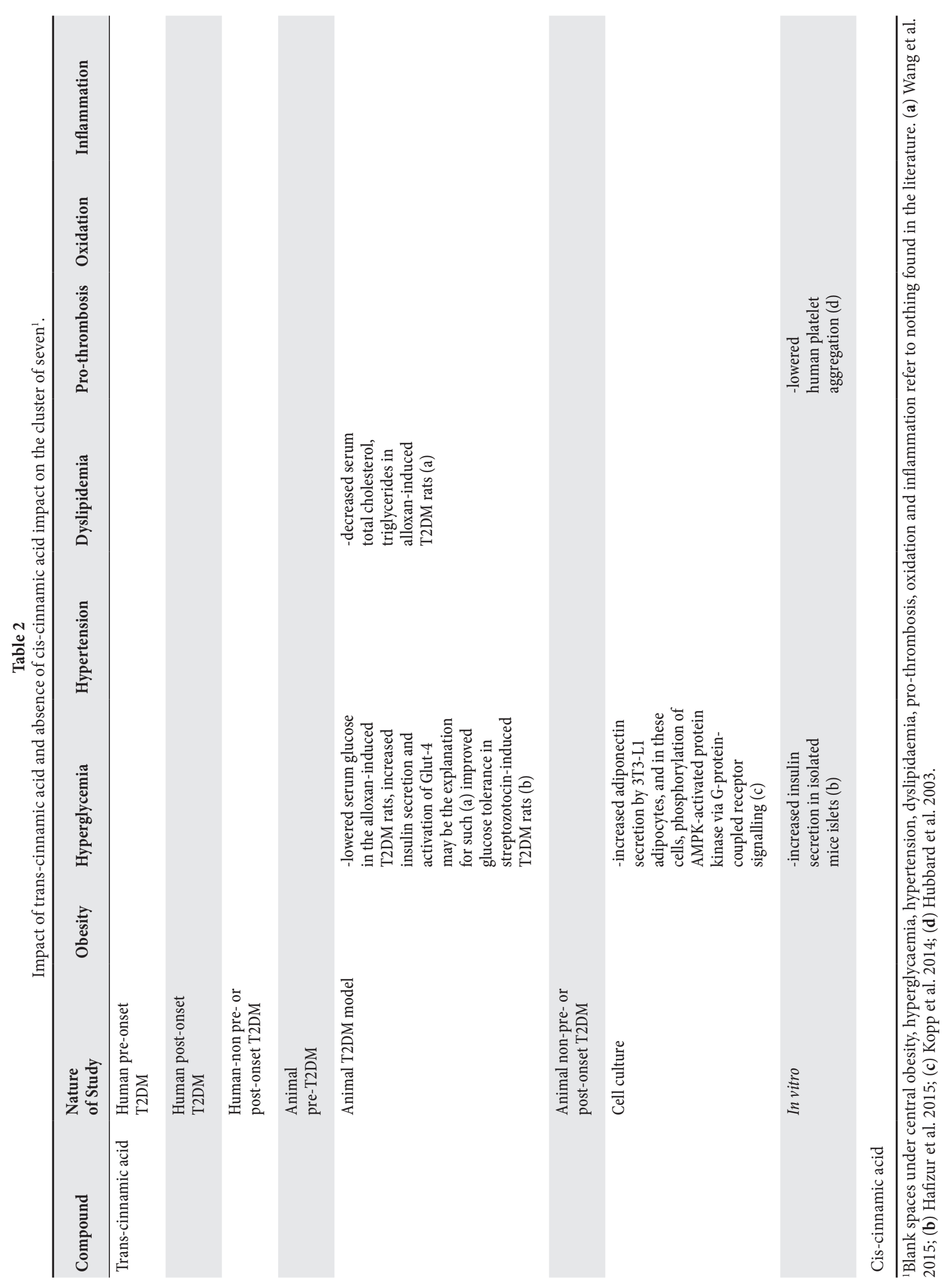




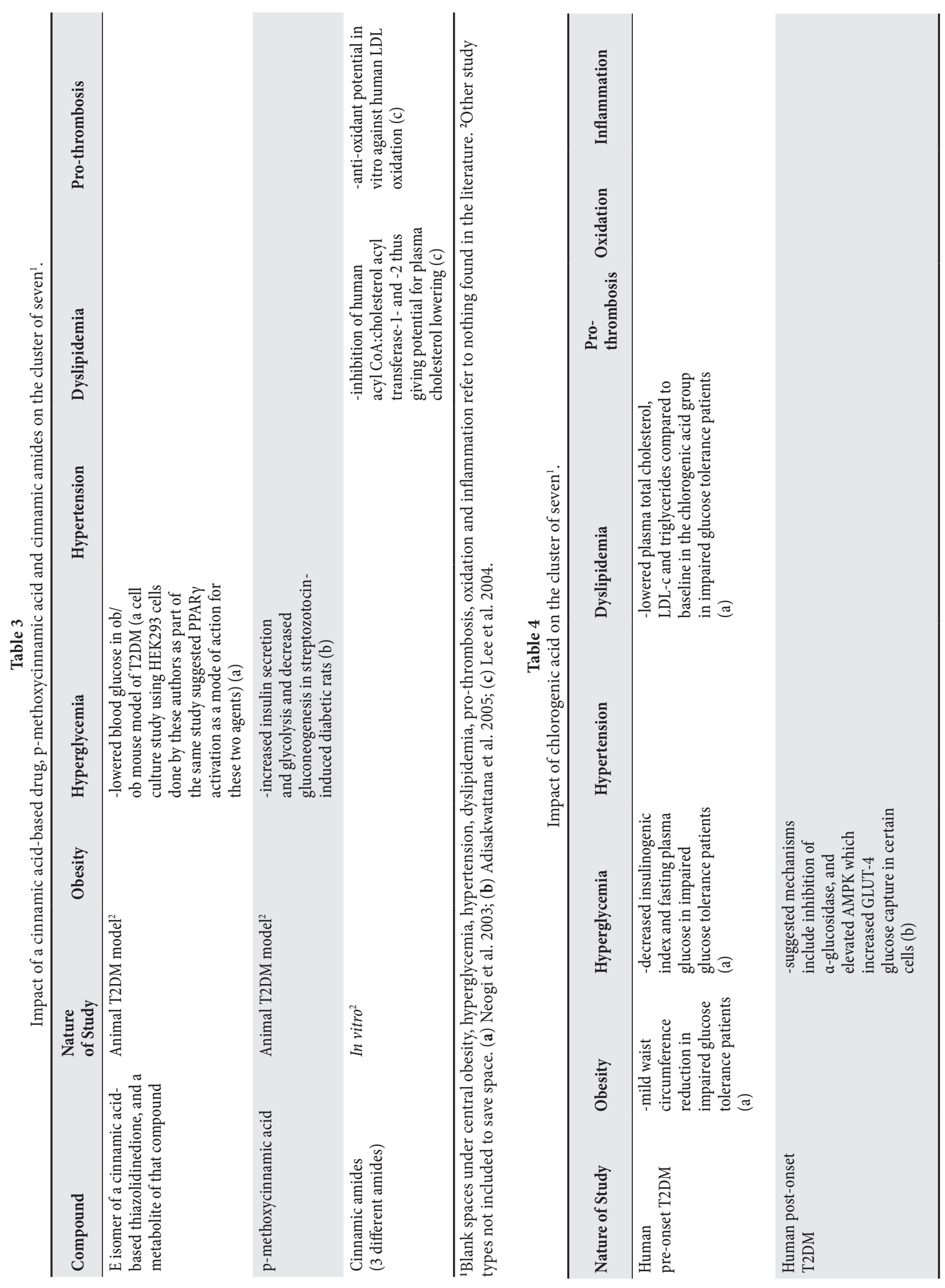





$\frac{\mathscr{\Xi}}{\vdots}$ 


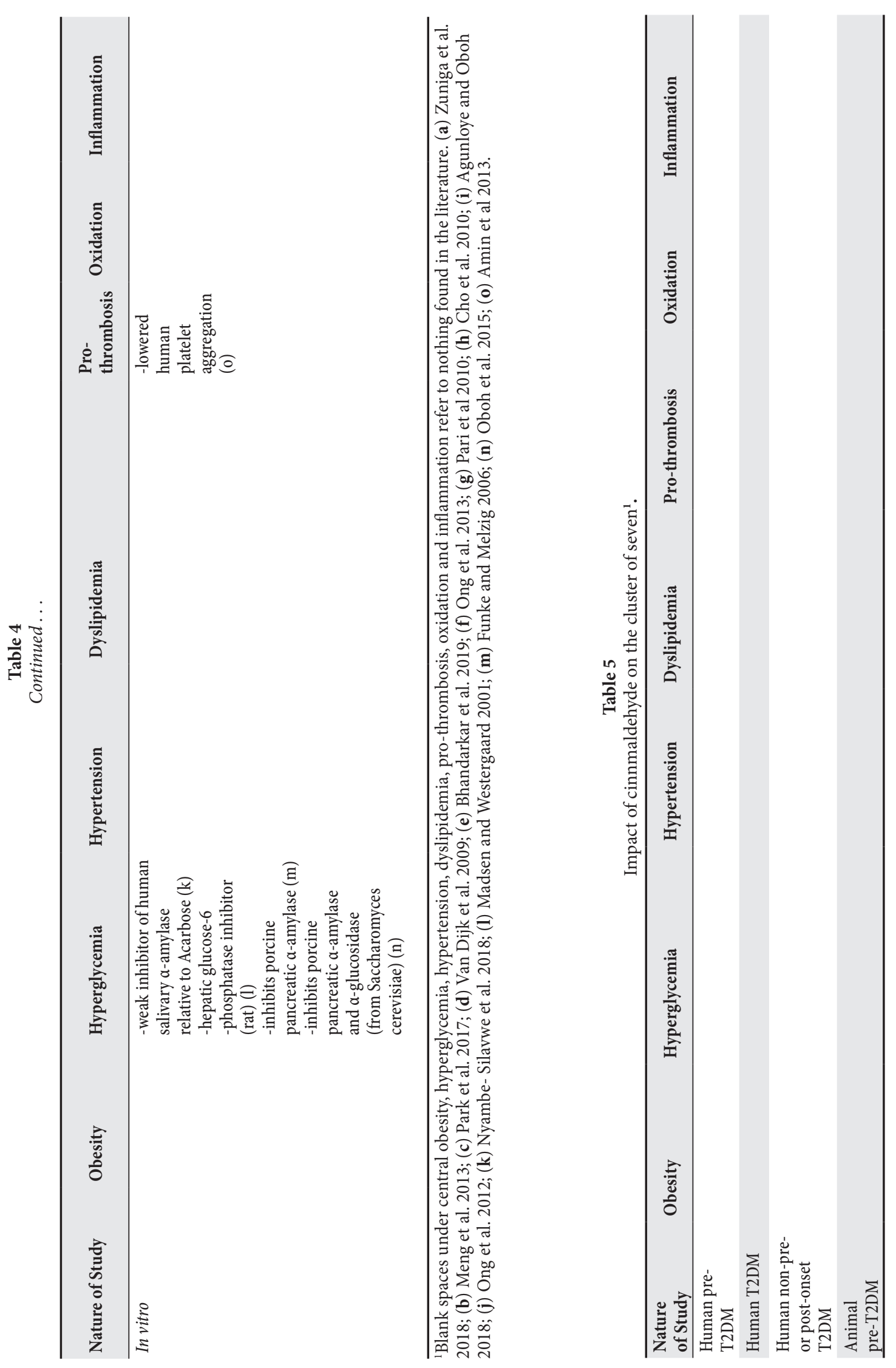




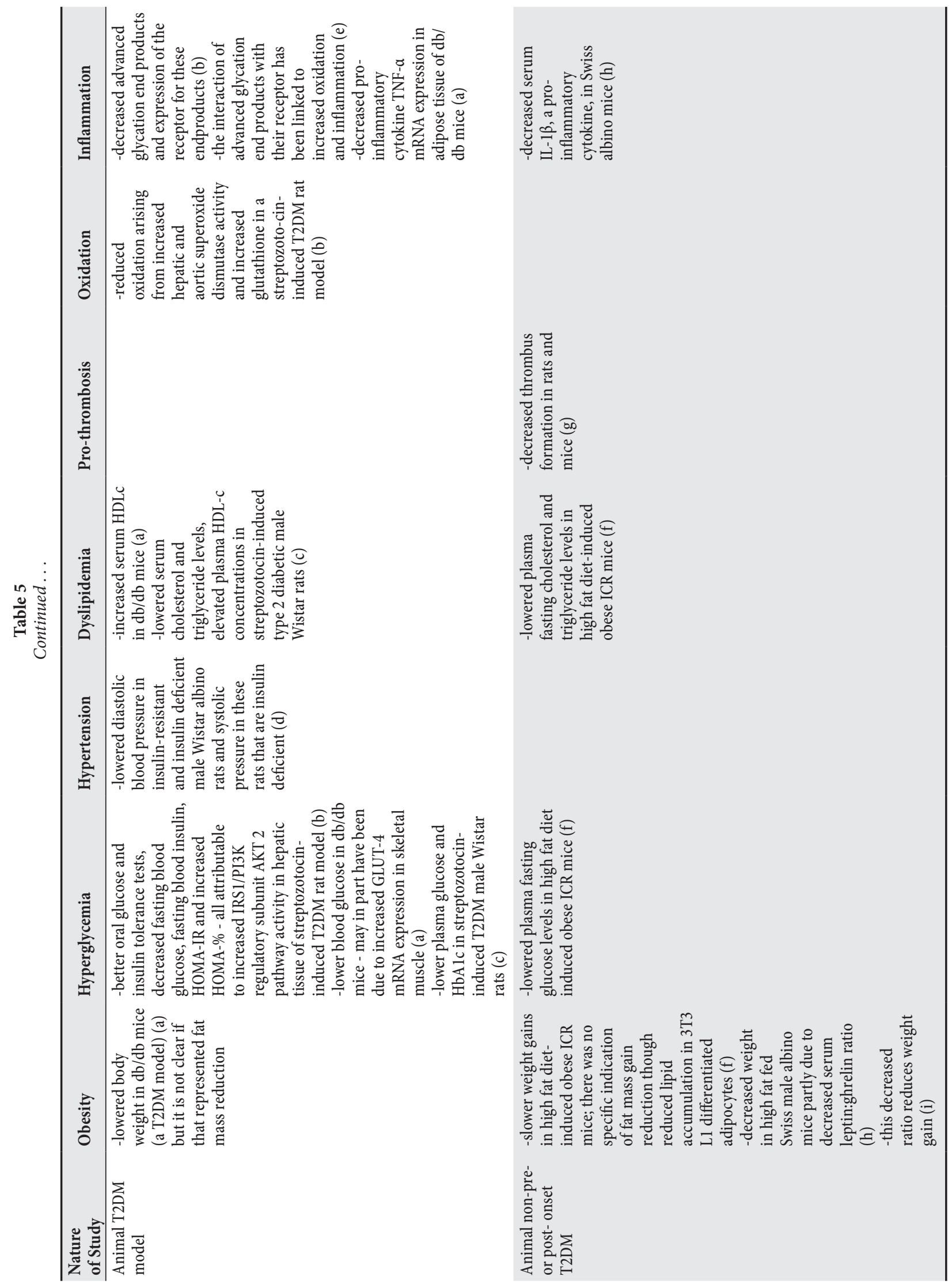



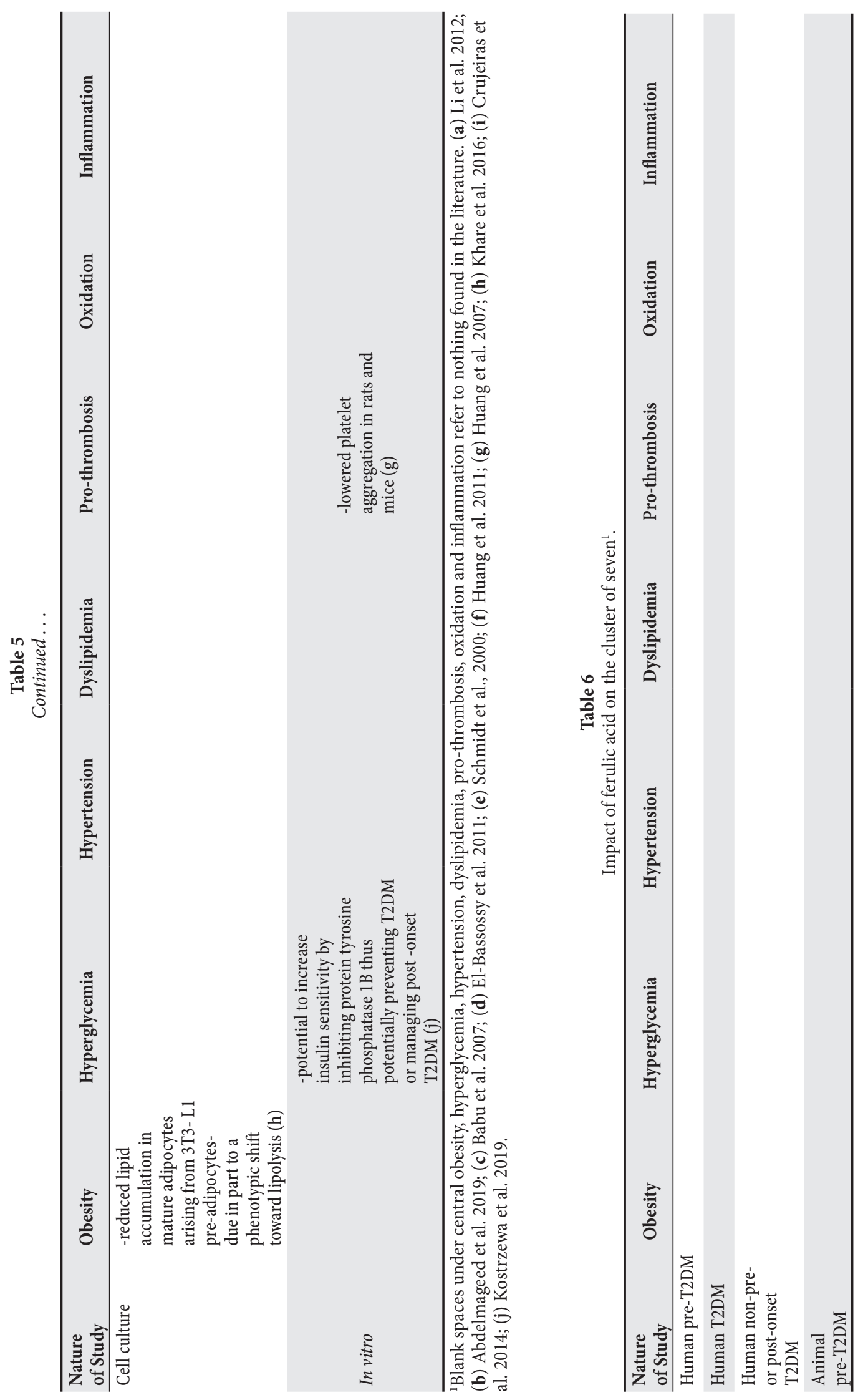


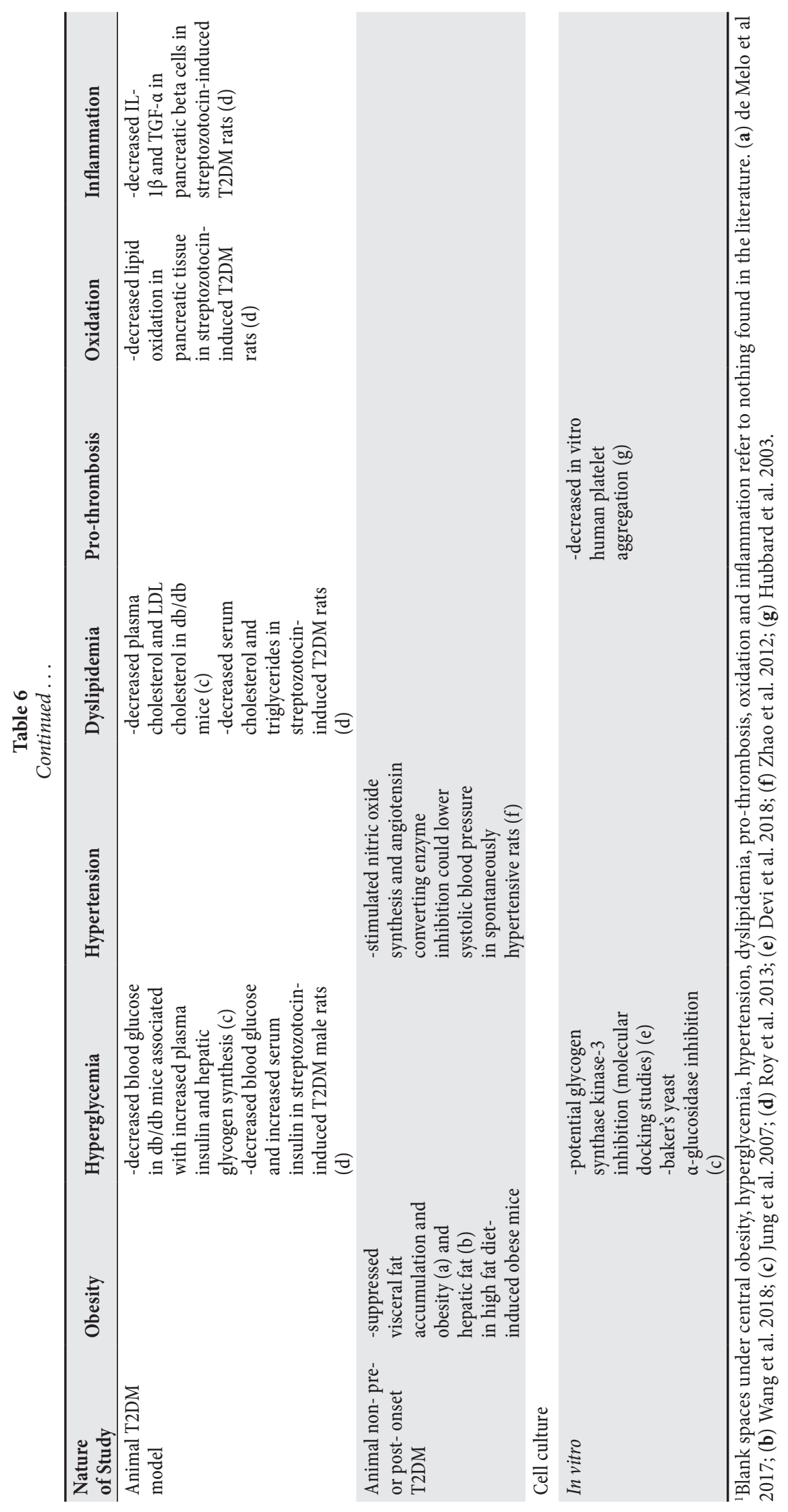




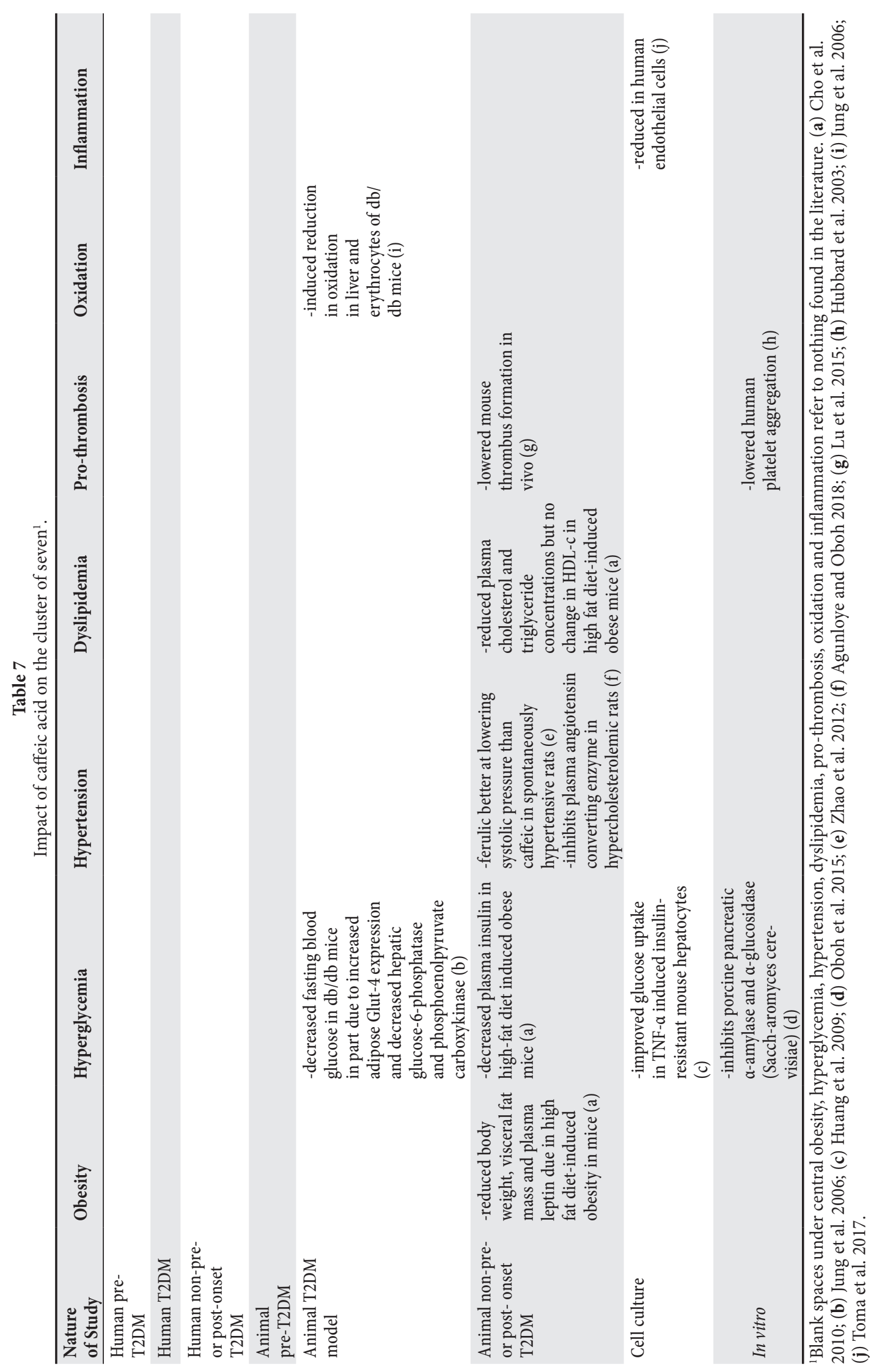




\section{References}

Abdelmageed ME, Shehatou GS, Abdelsalam RA, Suddek GM, Salem HA. Cinnamaldehyde ameliorates STZ-induced rat diabetes through modulation of IRS1/PI3K/AKT2 pathway and AGEs/RAGE interaction. N-S Arch Pharmacol Arch 392, 243-258, 2019.

Adisakwattana S, Sookkongwaree K, Roengsumran S, Petsom A, Ngamrojnavanich N, Chavasiri W, Deesamer S, Yibchok-anun S. Structure-activity relationships of trans-cinnamic acid derivatives on a-glucosidase inhibition. Bioorg Med Chem Lett 14, 2893-2896, 2004.

Adisakwattana S, Roengsamran S, Hsu WH, Yibchok-anuna S. Mechanisms of antihyperglycemic effect of p-methoxycinnamic acid in normal and streptozotocin-induced diabetic rats. Life Sciences 78, 406-412, 2005.

Adisakwattana S, Moonsan P, Yibchok-anun S. Insulin-releasing properties of a series of cinnamic acid derivatives in vitro and in vivo. J Agric Food Chem 56, 7838-7844, 2008.

Adisakwattana S, Chantarasinlapin P, Thammarat H, Yibchok-Anun S. A series of cinnamic acid derivatives and their inhibitory activity on intestinal a-glucosidase. J Enzyme Inhib Med Chem 24, 1194-1200, 2009.

Adisakwattana S. Cinnamic acid and its derivatives, mechanisms for prevention and management of diabetes and its complications. Nutrients 9, pii E163, 2017.

Agunloye OM, Oboh G. Hypercholesterolemia, angiotensin converting enzyme and ecto-enzymes of purinergic system: Ameliorative properties of caffeic and chlorogenic acid in hypercholesterolemic rats. J Food Biochem 2018, e12604, 2018.

Amin RP, Kunaparaju N, Kumar S, Taldone T, Barletta MA, Zito SW. Structure elucidation and inhibitory effects on human platelet aggregation of chlorogenic acid from Wrightia tinctoria. J Complement Integr Med 10, 97-104, 2013.

Arlt W, Neogi P, Gross C, Miller WL. Cinnamic acid based thiazolidinediones inhibit human P450c17 and $3 \beta$-hydroxysteroid dehydrogenase and improve insulin sensitivity independent of PPAR $\gamma$ agonist activity. J Mol Endocrinol 32, 425-436, 2004.

Austin RP. Polypharmacy as a risk factor in the treatment of type 2 diabetes. Diabetes Spectr 18, 13-16, 2006.

Avogaro A, Fadini GP, Gallo A, Pagnin E, de Kreutzenberg S. Endothelial dysfunction in type two diabetes mellitus. Nutr, Metabol Cardiovasc Dis 16(Suppl), S39-S45, 2006.

Azuma K, Heilbronn LK, Albu JB, Smith SR, Ravussin E, Kelley DE. Adipose tissue distribution in relation to insulin resistance in type two diabetes. Am J Physiol Endocrinol Metab 293, E435-E442, 2007.

Babu PS, Prabuseenivasan S, Ignacimuthu S. Cinnamaldehyde--a potential antidiabetic agent. Phytomedicine 14, 15-22, 2007.

Barre DE, Mizier-Barre KA, Stelmach E, Hobson J, Griscti O, Rudiuk A, Muthuthevar D. Flaxseed lignan complex administration in older human type 2 diabetes patients manages central obesity and prothrombosis-an invitation to further investigation into polypharmacy reduction. J Nutr Metab 2012, 585170, 2012.

Beckman JA, Creager MA, Libby P. Diabetes and atherosclerosis: epidemiology, pathophysiology and management. JAMA 287, 2570-2581, 2002.

Bel-Rhlid R, Thapa D, Kraehenbuehl K, Hansen CE, Fischer L. Biotransformation of caffeoyl quinic acids from green coffee extracts by Lactobacillus johnsonii NCC 533. AMB Express 3, 28, 2013.

Bhandarkar NS, Brown L, Panchal SK. Chlorogenic acid attenuates high-carbohydrate, high-fat diet-induced cardiovascular, liver, and metabolic changes in rats. Nutr Res 62, 78-88, 2019.

Boudjeltia KZ, Legssyer I, Antwerpen PV, Kisoka RL, Babar S, Moguilevsky N, Delree P, Ducobu J, Remacle C, Vanhaeverbeek M, Brohee D. Triggering of inflammatory response by myeloperoxidase-oxidized LDL. Biochem Cell Biol 84, 805-812, 2006.

Brown NJ, Vaughan DE. Angiotensin-converting enzyme inhibitors. Circulation 97, 1411-1420, Review, 1998.

Carr MC, Brunzell JD. Abdominal obesity and dyslipidemia in the metabolic syndrome: importance of type two diabetes and familial combined hyperlipidemia in coronary artery disease risk. J Clin Endocrinol Metab 89, 2601-2607, 2004

Caspary WF. Sucrose malabsorption in man after ingestion of a-glucosidehydrolase inhibitor. Lancet 1, 1231-1233, 1978.

Caspary WF, Graf S. Inhibition of human intestinal a-glucosidehydrolases by a new complex oligosaccharide. Res Exp Med (Berlin) 175, 1-6, 1979.

Cavelti-Weder C, Timper K, Seelig E, Keller C, Osranek M, Lassing U, Spohn G, Maurer P, Muller P, Jennings GT, Willers J, Saudan P, Donath MY, Bachmann MF. Development of an interleukin- $1 \beta$ vaccine in patients with type 2 diabetes. Mol Ther 24, 1003-1012, 2016. 
Chen K, Pittman RN, Popel AS. Nitric oxide in the vasculature: where does it come from and where does it go? A quantitative perspective. Antiox Redox Signal 10, 1185-1198, 2008.

Cho AS, Jeon SM, Kim MJ, Yeo J, Seo KI, Choi MS, Lee MK. Chlorogenic acid exhibits anti-obesity property and improves lipid metabolism in high-fat diet-induced-obese mice. Food Chem Toxicol 48, 937-943, 2010.

Cicero AF, Colletti A. Role of phytochemicals in the management of metabolic syndrome. Phytomed 23, 1134-1144, 2016.

Crujeiras AB, Diaz-Lagares A, Abete I, Goyenechea E, Amil M, Martinez JA, Casanueva FF. Pre-treatment circulating leptin/ghrelin ratio as a non-invasive marker to identify patients likely to regain the lost weight after an energy restriction treatment. J Endocrinol Invest 37, 119-126, 2014.

Dandona P, Aljada A, Chaudhuri A, Mohanty P, Garg R. Metabolic syndrome: a comprehensive perspective based on interactions between obesity, diabetes, and inflammation. Circulation 111, 1448-1454, 2005.

de Melo TS, Lima PR, Carvalho KM, Fontenele TM, Solon FR, Tome AR, de Lemos TL, da Cruz Fonseca SG, Santos FA, Rao VS, de Queiroz MG. Ferulic acid lowers body weight and visceral fat accumulation via modulation of enzymatic, hormonal and inflammatory changes in a mouse model of high-fat diet-induced obesity. Braz J Med Biol Res 50, e56302, 2017.

Del Rio D, Stalmach A, Calani L, Crozier A. Bioavailability of coffee chlorogenic acids and green tea flavan-3-ols. Nutrients 2, 820-833, 2010.

Devaraj S, Tang R, Adams-Huet B, Harris A, Seenivasan T, de Lemos JA, Jialal I. Effect of high-dose alpha-tocopherol supplementation on biomarkers of oxidative stress and inflammation and carotid atherosclerosis in patients with coronary artery disease. Am J Clin Nutr 86, 1392-1398, 2007.

Devi VR, Sharmila C, Subramanian S. Molecular docking studies involving the inhibitory effect of gymnemic acid, trigonelline and ferulic acid, the phytochemicals with antidiabetic properties, on glycogen synthase kinase 3 ( $\alpha$ and $\beta$ ). J Appl Pharm Sci 8, 150-160, 2018.

Dunn JD. Diabetes pharmacy management, balancing safety, cost, and outcomes. Amer J Manag Care 16 (7 Suppl), S201-206, 2010.

El-Bassossy HM, Fahmy A, Badawy D. Cinnamaldehyde protects from the hypertension associated with diabetes. Food Chem Toxicol 49, 3007-3012, 2011.

Erkelens DW. Insulin resistance syndrome and type 2 diabetes mellitus. Am J Cardiol 88(suppl) 38J-42J, 2001.

Foti M, Piatelli M, Tiziana Baratta M, Ruberto G. Flavonoids, coumarins, and cinnamic acids as antioxidants in a micellar system. structure-activity relationship. J Agric Food Chem 44, 497-501, 1996.

Funke I, Melzig MF. Traditionally used plants in diabetes therapy - phytotherapeutics as inhibitors of $\alpha$-amylase activity. Brazi J Pharmacog 16, 1-5, 2006.

Gonthier MP, Remesy C, Scalbert A, Cheynier V, Souquet JM, Poutanen K, Aura AM. Microbial metabolism of caffeic acid and its esters chlorogenic and caftaric acids by human faecal microbiota in vitro. Biomed Pharmacother 60, 536-540, 2006.

Gresele P, Guglielmini G, De Angelis M, Ciferri S, Ciofetta M, Falcinelli E, Lalli C, Ciabattoni G, Davì G, Bolli GB. Acute, short-term hyperglycemia enhances shear stress-induced platelet activation in patients with type II diabetes mellitus. J Am Coll Cardiol 41, 1013-1020, 2003.

Grundy SM. Metabolic syndrome, connecting and reconciling cardiovascular and diabetes worlds. J Amer Coll Cardiol 47, 1093-1100, 2006a.

Grundy SM. Drug therapy of the metabolic syndrome: minimizing the emerging crisis in polypharmacy. Nat Rev Drug Discov 5, 295-309, 2006b.

Hafizur RM, Hameed A, Shukrana M, Raza SA, Chishti S, Kabir N, Siddiqui RA. Cinnamic acid exerts anti-diabetic activity by improving glucose tolerance in vivo and by stimulating insulin secretion in vitro. Phytomed 22, 297-300, 2015.

Huang J, Wang S, Luo X, Xie Y, Shi X. Cinnamaldehyde reduction of platelet aggregation and thrombosis in rodents. Thromb Res 119, 337-342, 2007.

Huang DW, Shen SC, Wu JSB. Effects of caffeic acid and cinnamic acid on glucose uptake in insulin-resistant mouse hepatocytes. J Agric Food Chem 57, 3666-3673, 2009.

Huang ES, Karter AJ, Danielson KK, Warton EM, Ahmed AT. The association between the number of prescription medications and incident falls in a multi-ethnic population of adult type-2 diabetes patients, the diabetes and aging study. J Gen Intern Med 25, 141-146, 2010.

Huang B, Yuan HD, Kim DY, Quan HY, Chung SH. Cinnamaldehyde prevents adipocyte differentiation and adipogenesis via regulation of peroxisome proliferator-activated receptor- $\gamma$ (PPAR $\gamma$ ) and AMP-activated protein kinase (AMPK) pathways. J Agric Food Chem 59, 3666-3673, 2011. 
Hubbard GP, Wolffram S, Lovegrove JA, Gibbins JM. The role of polyphenolic compounds in the diet as inhibitors of platelet function. Proc Nutr Soc 62, 469-478, 2003.

Jung UJ, Lee MK, Park YB, Jeon SM, Choi MS. Antihyperglycemic and antioxidant properties of caffeic acid in $\mathrm{db} / \mathrm{db}$ mice. J Pharmacol Exp Ther 318, 476-483, 2006.

Jung EH, Kim SR, Hwang IK, Ha TY. Hypoglycemic effects of a phenolic acid fraction of rice bran and ferulic acid in C57BL/KsJ-db/db mice. J Agric Food Chem 55, 9800-9804, 2007.

Kadowaki T, Yamauchi T. Adiponectin and adiponectin receptors. Endocrin Rev 26, 439-451, 2005.

Kahn BB, Alquier T, Carling D, Hardie DG. AMP-activated protein kinase: ancient energy gauge provides clues to modern understanding of metabolism. Cell Metab 1, 15-25, 2005.

Khare P, Jagtap S, Jain Y, Baboota RK, Mangal P, Boparai RK, Bhutani KK, Sharma SS, Premkumar LS, Kondepudi KK, Chopra K, Bishnoi M. Cinnamaldehyde supplementation prevents fasting-induced hyperphagia, lipid accumulation, and inflammation in high-fat diet-fed mice. Biofactors 42, 201-211, 2016.

Kopp C, Singh SP, Regenhard P, Muller U, Sauerwein H, Mielenz M. Trans-cinnamic acid increases adiponectin and the phosphorylation of AMP-activated protein kinase through G-protein-coupled receptor signaling in 3T3L1 adipocytes. Int J Mol Sci 15, 2906-2915, 2014.

Kostrzewa T, Przychodzen P, Gorska-Ponikowska M, Kuban-Jankowska A. Curcumin and cinnamaldehyde as PTP1B inhibitors with antidiabetic and anticancer potential. Anticancer Res 39, 745-749, 2019.

Krauss RM. Lipids and lipoproteins in patients with type 2 diabetes. Diabetes Care 27, 1496-1504, 2004.

Kurth-Kraczek EJ, Hirshman MF, Goodyear LJ, Winder WW. 5’ AMP-activated protein kinase activation causes GLUT4 translocation in skeletal muscle. Diabetes 48, 1667-1671, 1999.

Lakshmi BS, Sujatha S, Anand S, Sangeetha KN, Narayanan RB, Katiyar C, Kanaujia A, Duggar R, Singh Y, Srinivas K, Bansal V, Sarin S, Tandon R, Sharma S, Singh S. Cinnamic acid, from the bark of Cinnamomum cassia, regulates glucose transport via activation of GLUT4 on L6 myotubes in a phosphatidylinositol 3-kinaseindependent manner. J Diabetes 1, 99-106, 2009.

Lee JS, Jeon SM, Park EM, Huh TL, Kwon OS, Lee MK, Choi MS. Cinnamate supplementation enhances hepatic lipid metabolism and antioxidant defense systems in high cholesterol-fed rats. J Med Food 6,183-191, 2003.

Lee S, Han JM, Kim H, Kim E, Jeong TS, Lee WS, Cho KH. Synthesis of cinnamic acid derivatives and their inhibitory effects on LDL-oxidation, acyl-CoA, cholesterol acyltransferase-1 and -2 activity and decrease of HDLparticle size. Bioorg Med Chem Lett 14, 4677-4681, 2004.

Li J, Liu T, Wang L, Guo X, Xu T, Wu L, Qin L, Sun W Antihyperglycemic and antihyperlipidemic action of cinnamaldehyde in C57BLKS/J db/db mice. J Trad Chin Med 32, 446-452, 2012.

Lu Y, Li Q, Liu YY, Sun K, Fan JY, Wang CS, Han JY. Inhibitory effect of caffeic acid on ADP-induced thrombus formation and platelet activation involves mitogen-activated protein kinases. Sci Rep 5, 13824, 2015.

Madsen P, Westergaard N. Glucose-6-phosphatase inhibitors for the treatment of type 2 diabetes. Expert Opin Ther Pat 11, 1429-1441, 2001.

Meng S, Cao J, Feng Q, Peng J, Hu Y. Roles of chlorogenic acid on regulating glucose and lipids metabolism: a review. Evid Based Complement Alternat Med 2013, 801457, 2013.

Mnafgui K, Derbali A, Sayadi S, Gharsallah N, Elfeki A, Allouche N. Anti-obesity and cardioprotective effects of cinnamic acid in high fat diet- induced obese rats. J Food Sci Tech 52, 4369-4377, 2015.

Neogi P, Lakner FJ, Medicherla S, Cheng J, Dey D, Gowri M, Nag B, Sharma SD, Pickford LB, Gross C. Synthesis and structure-activity relationship studies of cinnamic acid-based novel thiazolidinedione antihyperglycemic agents. Bioorg Med Chem 11, 4059-4067, 2003.

Nyambe-Silavwe H, Williamson G. Chlorogenic and phenolic acids are only very weak inhibitors of human salivary a-amylase and rat intestinal maltase activities. Food Res Int 113, 452-455, 2018.Oboh G, Agunloye OM, Adefegha SA, Akinyemi AJ, Ademiluyi AO. Caffeic and chlorogenic acids inhibit key enzymes linked to type 2 diabetes (in vitro): a comparative study. J Basic Clin Physiol Pharmacol 26, 165-170, 2015.

Olthof MR, Hollman PC, Katan MB. Chlorogenic acid and caffeic acid are absorbed in humans. J Nutr 131, 66-71, 2001.

Ong KW, Hsu A, Tan BK. Chlorogenic acid stimulates glucose transport in skeletal muscle via AMPK activation: a contributor to the beneficial effects of coffee on diabetes. PLoS One 7, e32718, 2012.

Ong KW, Hsu A, Tan BK. Anti-diabetic and anti-lipidemic effects of chlorogenic acid are mediated by ampk activation. Biochem Pharmacol 85, 1341-1351, 2013.

Pan A, Sun J, Chen Y, Ye X, Li H, Yu Z, Wang Y, Gu W, Zhang X, Chen X, Demark-Wahnefried W, Liu Y, Lin X. Effects of a flaxseed-derived lignan supplement in type 2 diabetic patients, a randomized, double-blind, cross-over trial. PLoS One 2, e1148, 2007. 
Pari L, Karthikesan K, Menon VP. Comparative and combined effect of chlorogenic acid and tetrahydrocurcumin on antioxidant disparities in chemical induced experimental diabetes. Mol Cell Biochem 341, 109-117, 2010.

Park I, Ochiai R, Ogata H, Kayaba M, Hari S, Hibi M, Katsuragi Y, Satoh M, Tokuyama K. Effects of subacute ingestion of chlorogenic acids on sleep architecture and energy metabolism through activity of the autonomic nervous system: a randomised, placebo-controlled, double-blinded cross-over trial. $\mathrm{Br} \mathrm{J}$ Nutr 117, 979-984, 2017.

Plumb GW, Garcia-Conesa MT, Kroon PA, Rhodes M, Ridley S and Williamson G. Metabolism of chlorgenic acid by human plasma liver, intestine and gut microflora. J Sci Food Agric 79, 390-392, 1999.

Roy S, Metya SK, Sannigrahi S, Rahaman N, Ahmed F. Treatment with ferulic acid to rats with streptozotocininduced diabetes: effects on oxidative stress, pro-inflammatory cytokines, and apoptosis in the pancreatic $\beta$ cell. Endocrine 44, 369-379, 2013.

Schmidt AM, Yan SD, Yan SF, Stern DM. The biology of the receptor for advanced glycation end products and its ligands. Biochim Biophys Acta 1498, 99-111, 2000.

Steinberg D. Antioxidants in the prevention of human atherosclerosis. Summary of the proceedings of a National Heart, Lung, and Blood Institute Workshop: September 5-6, 1991, Bethesda, Maryland. Circulation 85, 2337-2344, 1992.

Toma L, Sanda GM, Niculescu LS, Deleanu M, Stancu CS, Sima AV. Caffeic acid attenuates the inflammatory stress induced by glycated LDL in human endothelial cells by mechanisms involving inhibition of AGEreceptor, oxidative, and endoplasmic reticulum stress. Biofactors 43, 685-697, 2017.

Tomas-Barberan F, Garcia-Villalba R, Quartieri A, Raimondi S, Amaretti A, Leonardi A, Rossi M. In vitro transformation of chlorogenic acid by human gut microbiota. Mol Nutr Food Res 58, 1122-1131, 2014.

van Bruggen R, Gorter K, Stolk RP, Zuithoff P, Klungel OH, Rutten GE. Refill adherence and polypharmacy among patients with type 2 diabetes in general practice. Pharmacoepidemiol Drug Safe 18, 983-991, 2009.

van Dijk AE, Olthof MR, Meeuse JC, Seebus E, Heine RJ, van Dam RM. Acute effects of decaffeinated coffee and the major coffee components chlorogenic acid and trigonelline on glucose tolerance. Diabetes Care 32,1023-1025, 2009.

Wang H, Li Q, Deng W, Omari-Siaw E, Wang Q, Wang S, Wang S, Cao X, Xu X, Yu J. Self-nanoemulsifying drug delivery system of trans-cinnamic acid, formulation development and pharmacodynamic evaluation in alloxan-induced type 2 diabetic rat model. Drug Develop Res 76, 82-93, 2015.

Wang W, Pan Y, Zhou H, Wang L, Chen X, Song G, Liu J, Li A. Ferulic acid suppresses obesity and obesityrelated metabolic syndromes in high fat diet- induced obese C57BL/6J mice. Food Agri Immunol 29, $1116-1125,2018$.

Witztum JL, Steinberg D. Role of oxidized low-density lipoprotein in atherogenesis. J Clin Invest 88, 1785-1792, 1991.

Wright E Jr, Scism-Bacon JL, Glass LC. Oxidative stress in type 2 diabetes: the role of fasting and postprandial glycaemia. Int J Clin Pract 60, 308-314, 2006.

Yoo KM, Lee C, Lo YM, Moon B. The hypoglycemic effects of American red ginseng (Panax quinquefolius L.) on a diabetic mouse model. J Food Sci 77, H147-H152, 2012.

Zhao G, Dharmadhikari G, Maedler K, Meyer-Hermann M. Possible role of interleukin- $1 \beta$ in type 2 diabetes onset and implications for anti-inflammatory therapy strategies. PLoS Computat Biol 10, e1003798, 2014.

Zhao Y, Wang J, Ballevre O, Luo H, Zhang W. Antihypertensive effects and mechanisms of chlorogenic acids. Hypertens Res 35, 370-374, 2012.

Zuniga LY, Aceves-de la Mora MCA, Gonzalez-Ortiz M, Ramos-Nunez JL, Martinez-Abundis E. Effect of chlorogenic acid administration on glycemic control, insulin secretion, and insulin sensitivity in patients with impaired glucose tolerance. J Med Food 21, 469-473, 2018. 